УДК 81'42

ББК 81

DOI: https://doi.org/10.17308/lic.2021.2/3425

\title{
МАРКЕМЫ БРИТАНСКОЙ ПРОЗЫ: НОВЫЙ ШАГ НА ПУТИ К УНИВЕРСАЛИЯМ
}

(Рец. на кн.: Артемова О. Г. Языковые ключи к английской литературе от Шекспира до Фаулза. Воронеж : НАУКА-ЮНИПРЕСС, 2020. 596 с.)

\author{
А. В. Кашкина
}

\section{MARKEMES OF BRITISH PROSE: A NEW STEP ON THE WAY TO UNIVERSALIA (Review of Artyomova O. G. Jazykovyje kliuchi k anglijskoj literature ot Shekspira do Faulza [Language keys to English literature from Shakespeare to Fowls]. Voronezh : NAUKA-UNIPRESS, 2020. 596 p.)}

\author{
A. V. Kashkina
}

В 2007 г., с введением понятия индекса тематической маркированности [1], был заложен первый камень в фундамент нового научного направления маркемологии, или маркемного анализа. С тех пор продолжается его постоянное строительство, выражаясь в оттачивании программного и математического инструментария, упрочении теоретической базы, вовлечении новых материалов в сферу интересов исследования. Рецензируемая работа представляет собой очередной этаж в непрерывно растущем и совершенствующемся здании маркемологии.

В работе представлен беспрецедентный по охвату материала и аспектам его изучения анализ лексики английских прозаических текстов - 2301 произведение 128 авторов с XVII по XX в., сгруппированных в 8 полувековых хронологических срезов, составляющие более 173 млн словоупотреблений. В основе применяемых методов лежит понятие маркемь [2] - слова в тексте, удовлетворяющего набору грамматических, стилистических и семантических критериев и обладающего в данном тексте высоким значением индекса текстуальной маркированности (зависящим от частоты и длины слова).

В далеком 2010 г. в статье «Сравнительный маркемный анализ: проблемы и перспективы» [3] ста- вился вопрос о принципиальной возможности исследования англоязычных текстов средствами маркемного анализа и сопоставлении полученных результатов с данными по русской художественной литературе. Рецензируемая монография является в определенном смысле положительным ответом на этот вопрос. Действительно, имевшийся на тот момент инструментарий маркемологии был приспособлен под русскоязычный материал. В настоящее время, благодаря разработанной А. С. Гусельниковой под руководством И. Е. Ворониной программе ProTemAL-Engl [4], стала возможной обработка крупных массивов текстов на английском языке. Другая отмеченная в статье проблема - отсутствие взаимно-однозначного соответствия между значениями русских и английских лексем, которое представляет собой препятствие как для сопоставительного маркемного анализа, так и для их семантической классификации - решается в рецензируемой работе при помощи обращения к метаязыку. В качестве последнего используется русский, семантика же лексем устанавливается при помощи их переводных эквивалентов по словарю Мюллера. Можно, разумеется, настаивать на использовании толковых англоязычных словарей, однако именно такой подход открывает перспективы для межъязы-

(C) Кашкина А. В., 2021

Контент доступен под лицензией Creative Commons Attribution 4.0 License.

The content is available under Creative Commons Attribution 4.0 License. 
кового и межлитературного сравнения. Еще одно из отмеченных в вышеупомянутой статье препятствий для исследователя англоязычных текстов - отсутствие в английском языке падежных флексий, что затрудняет автоматизацию выбора маркем (в русском языке сложность представляют лишь омонимичные формы именительного и винительного падежей для неодушевленных существительных среднего и мужского рода). Даже если предположить, что каждая маркема встречается у данного автора лишь 2 раза, это потребовало бы анализа 12800 контекстов словоупотребления (в реальности, естественно, их количество на порядок выше). Можно лишь восхищаться тщательностью и скрупулезностью автора рецензируемой работы, не остановившегося перед громадным объемом контекстных проверок. Непрерывное обращение к изучаемым произведениям снимает и другую проблему - необходимость разграничения омонимии и полисемии. Отдельные значения одного слова просто соотносятся с разными метасловами, а иногда и «разносятся» по различным семантическим блокам (например, fortune 'богатство' входит в блок социальных маркем, a fortune 'удача' относится к фундаментальным понятиям), трактуясь, соответственно, как разные маркемы). Наконец, еще одна сложность - отождествление современных форм слов с их устаревшими эквивалентами (упоминающееся в [5]) - носит чисто формальный характер и решается простым приведением всех словоформ в соответствие с нормами современной английской орфографии.

Структура монографии в общих чертах сходна с используемой в маркемных исследованиях русской поэзии и прозы: вначале на основе маркемных списков авторов данного среза составляются общие срезовые списки, из которых в свою очередь строится интегральный маркемный список, содержащий наиболее информативные маркемы за всю историю развития литературы (показателем информативности являются количество употребивших маркему авторов и ее суммарный ИнТеМ). Рассматриваются как маркемы сами по себе, так и включающие их семантические блоки, выявляемые при помощи толкования метаслов в Словаре русского языка под редакцией А. П. Евгеньевой и соответствующие принятой в настоящее время классификации маркем. Именно такое единообразие, как структурное, так и методологическое, делает возможным исследования, подобные совместной работе А. А. Кретова и О. Г. Артемовой [6], где сопоставляется динамика развития маркемной лексики русской и английской прозы.

Квантитативно-квалитативный характер исследования подразумевает повсеместное применение такого метода, как стратификация (по принципу «ядро - периферия», «устойчивость - изменчивость»), что подкрепляет научную достоверность достигнутых результатов и позволяет отделить случайное от закономерного. В сферу внимания лингвиста, помимо индивидуальных особенностей маркемной лексики английских прозаиков и специфики отдельных хронологических срезов, попадают и взаимоотношения авторов, как в пределах современной им эпохи, так и межсрезовые, а также их роль в данном срезе и литературном процессе Великобритании в целом. В этом плане необходимо отметить значительно более проработанный, отточенный инструментарий, использующийся для описания этих отношений. Прежде всего, при помощи такого параметра, как индекс общесрезовой адекватности, определяются наиболее типичные представители конкретных хронологических срезов (в частности, для второй половины XIX в. это Диккенс, Дж. Мур, Элиот, Троллоп, Майн Рид, Стивенсон) и британской литературы в целом (Стил, Силлитоу), и напротив, наиболее нехарактерные, уникальные - Балард, Чапмен и Мильтон. Далее, общность текстов авторов одного периода определяется количеством связующих маркем и их весом в произведениях данных писателей; при этом устанавливаются связи различной силы, как одно-, так и двусторонние, которые свидетельствуют об общности тематики. Аналогичные отношения рассматриваются и между срезовыми маркемными списками. Так выделяется та маркемная лексика, которая проходит красной нитью через всю историю английской литературы (главные из них связующие доминанта и вице-доминанта understanding и satisfaction), и те авторы, которые обеспечивают ее целостность. Это дает возможность также с математической точностью установить периодизацию британской литературы - эпохи становления (XVII - начало XVIII в.), расцвета (сер. XVIII - XIX в.) и упадка (XX в.). Необходимо отметить крайне удачное решение в плане визуализации - использование нагруженных графов, что позволяет наглядно отобразить и направление, и силу связи.

Наконец, для выявления отношений «литературной преемственности» используется как проспективное, так и ретроспективное генеалогическое исследование (о методе см. подробнее, например [7]), что повышает достоверность полученных результатов. Для дополнительного подтверждения полученной картины генетического родства исследователь обращается к анализу обоюдных связей авторов, входящих в смежные хронологические срезы. За счет этого обнаруживаются те писатели, которые обеспечивают литературную «связь поколений» (выступая одновременно в качестве предка в ретроспективном исследовании и потомка в проспективном) - Скотт, Гринвуд и Конан Дойль, чей «статус» подтверждает наличие обоюдных связей с авторами предшествующего и последующего хронологических срезов. 
Рациональным решением является то, что автор не пытается привести результаты исследования в соответствие с данными литературоведения либо использовать последние для их обоснования, истолкования, уточнения или подкрепления. Все задачи исследования - выявление наиболее типичных представителей того или иного периода, установление отношений преемственности в творчестве, анализ динамики семантических групп и т. п. - решаются исключительно с помощью аппарата маркемологии, без привлечения сторонних инструментов или данных. Безусловно, взаимовыгодное сотрудничество литературоведения и маркемологии правомерно и небесполезно, однако выходит за рамки даже столь масштабной работы.

Наконец, еще одним неоспоримым плюсом работы является четкость, ясность, простота изложения, грамотное структурирование материала. В частности, все вновь вводимые термины маркемологии, которыми оперирует автор, подробно толкуются в специально отведенных пунктах работы. Такое простое и очевидное решение, как отдельные иллюстрации для отображения крупных ветвей генеалогического древа английской прозы, также способствует максимально наглядному представлению итогов исследования. Помимо графов и деревьев, широко применяются средства Excel - графики и гистограммы. Bсе эти особенности делают рецензируемую монографию доступной не только для узких специалистов, но и для широкого круга читателей, имеющих минимальную лингвистическую подготовку.

Результаты исследования, несомненно, будут полезны и в литературоведении, и в научной деятельности филолога. Но прежде всего, эта работа открывает поистине безграничные перспективы в области сопоставительного маркемного анализа, являясь очередной ступенью на пути к выявлению общеевропейских и мировых литературных универсалий.

\section{ЛИТЕРАТУРА}

1. Кретов А. А. Метод формального выделения тематически нейтральной лексики (на примере старославянских текстов) // Вестник Воронеж. гос. ун-та. Сер.: Системный анализ и информационные технологии. 2007. № 1. С. 81-90.

2. Кретов A. A. Понятие маркемы : методика выявления и практика использования // Универсалии русской литературы - 2 : сб. ст. / под ред. А. А. Фаустова ; Воронеж. гос. ун-т. Воронеж : Наука-Юнипресс, 2010. C. $138-153$.

3. Кашкина A. B. Сравнительный маркемный анализ : проблемы и перспективы // Язык, коммуникация и социальная среда : сб. науч. трудов. Воронеж : Воронежский государственный университет ; Изд. дом Алейниковых, 2010. Вып. 8. С. 228-235.
4. Гусельникова А. С., Воронина И. Е., Кретов А. А. Выделение тематически маркированной лексики в текстах на естественных языках // Информатика : проблемы, методология, технологии : материалы XV Междунар. науч.-метод. конф. Воронеж, 2015. С. 245-250.

5. Кашкина A. В. Проблема семантического отождествления синхронных и диахронных вариантов слова // Вестник Воронеж. гос. ун-та. Сер.: Лингвистика и межкультурная коммуникация. 2012. № 2. URL: https:// cyberle-ninka.ru/article/n/problema-semanticheskogo-otozhdestvleniya-sinhronnyh-i-diahronnyh-variantov-slova

6. Артемова О. Г., Кретов А. А. Маркемные траектории языка русской и английской художественной прозы // Вестник Воронеж. гос. ун-та. Сер.: Лингвистика и межкультурная коммуникация. 2018. № 1. С. 165-173.

7. Кретов А. А., Катов М. В., Фаустов А. А. Лингвостатистическая генеалогия в русской литературе XVIII начала XX в. // Проблемы компьютерной лингвистики : сб. науч. трудов / под ред. А. А. Кретова. Воронеж, 2010. Вып. 4. С. 114-125.

\section{REFERENCES}

1. Kretov A. A. Metod formal'nogo vydelenija tematicheski nejtral'noj leksiki (na primere staroslavyanskikh tekstov) [The method of formal extraction of thematically neutral lexemes (on example of Old Slavic texts)]. In: Vestnik Voronezhskogo gosudarstvennogo universiteta: Sistemnyj analiz i informatsionnye tekhnologii. 2007. No. 1. Pp. 81-90.

2. Kretov A. A. Ponyatije markemy: metodika vyjavlenija I praktika ispol'zovaniya [The concept of markeme: metods of detection and practical application]. In: Universalii russroj literatury. Ed. by Faustov A. A. Issue 2. Voronezh: Nauka-Junipress, Voronezh State University, 2010. Pp. 138-153.

3. Kashkina A. V. Sravnitel'nyj markemnyj analiz: problemy i perspektivy [Comparative markeme analysis: challenges and perspectives]. In: Jazyk, kommunikatsija $i$ sotsial'naja sreda. Issue 8. Voronezh: Voronezh State University; Izdatel'skij dom Alejnikovykh, 2010. Pp. 228235.

4. Gusel'nikova A. S. Vydelenije tematicheski markirovannoj leksiki v tekstakh na estestvennykh jazykakh [Extracting thematically marked lexemes from texts in natural language]. In: Informatika: problemy, metodologija, tekhnologii: materialy XV Mezhdunar. nauch.-metod. konf. Voronezh, 2015. Pp. 245-250.

5. Kashkina A. V. Problema semsnticheskogo otozhdestvlenija sinkhronnykh I diakhronnyh variantov slova [The problem of matching synchronic and diachronic word variants]. Available at: https://cyberleninka.ru/ article/n/problema-semanticheskogo-otozhdestvleniyasinhronnyh-i-diahronnyh-variantov-slova

6. Artyomova O. G., Kretov A. A. Markemnye traektorii jazyka russkoj I anglijskoj khudozhestvennoj literatury [Markeme trends in the languageof Russian and British literature]. In: Vestnik VGU. Lingvistika i mezhkul'turnaja kommunikatsija. 2018. No. 1. Pp. 165-173. 
7. Kretov A. A. Lingvostatisticheskaya genealogija v russkoj literature XVIII - nachala XX vv. [Linguostatistic genealogy of Russian literature from XVIII to beginning of

Кашкина А. В., кандидат филологических наук E-mail:shtil72@yandex.ru

Поступила в редакциию 28 февраля 2021 г.

Принята к публикации 22 марта 2021 г.

\section{Для иитирования:}

Кашкина A. В. Маркемы британской прозы: новый шаг на пути к универсалиям (Рец. на кн.: Артемова О. Г. Языковые ключи к английской литературе от Шекспира до Фаулза. Воронеж : НАУКА-ЮНИПРЕСС, 2020. 596 с.) // Вестник Воронежского государственного университета. Серия: Лингвистика и межкультурная коммуникация. 2021. № 2. C. 154-157. DOI: https://doi. org/10.17308/lic.2021.2/3425
XX century]. In: Problemy komp'juternoj lingvistiki. Ed. by A. A. Kretov. Issue 4. Voronezh, 2010. Pp. 114-125.

\author{
Kashkina A. V., Candidate of Philology \\ E-mail: shtil72@yandex.ru
}

Received: 28 February 2021

Accepted: 22 March 2021

\section{For citation:}

Kashkina A. V. Markemes of British prose: a new step on the way to universalia (Review of Artyomova O. G. Jazykovyje kliuchi k anglijskoj literature ot Shekspira do Faulza [Language keys to English literature from Shakespeare to Fowls]. Voronezh : NAUKA-UNIPRESS, 2020. 596 p.) Proceedings of Voronezh State University. Series: Linguistics and Intercultural Communication. 2021. No. 2. Pp. 154-157. DOI: https://doi.org/10.17308/lic.2021.2/3425 